\title{
Evaluation of South African Business Schools' Brand Management Strategies and Its Effect On Students
}

\author{
Colleen Biyela ${ }^{1}$, Prof Muhammad Hoque, $\mathbf{P h D}^{2}$ \\ ${ }^{1}$ Graduate School of Business \& Leadership, College of Law and Management Studies, \\ University of KwaZulu-Natal \\ ${ }^{2}$ Senior Research Associate, Management College of Southern Africa,
}

\begin{abstract}
The study aimed to investigate the brand management strategies that South African business schools use and the effect on student perceptions. This was a cross-sectional, quantitative study conducted among registered MBA students. Data were collected using the online program, Survey Monkey. Factor analysis revealed that student perceptions are largely influenced by three strategies, namely: Inspirational leadership, Seasonal Apprentice Mentorships, and Equitable Rewards. Brand positioning was identified as the most important requiring prompt and effective interventions to position the school's brand management strategies on the right track and realise the vision of being a business school of choice to candidates from all over South Africa and beyond. The study recommends a deeper understanding of the brand management strategies influencing student choice positively and improved communications with students.
\end{abstract}

Keywords: Balanced scorecard; consumer psychology; corporate communications; competitive edge. 


\section{INTRODUCTION}

Higher education progressively faces demands to be accountable to their stakeholders. Many business academics and administrators have intensely criticized business education's relevance to business and the community in general (Kagan, 2015). Business schools have not defined and measured outcomes and thus value-added to their programs. Business schools need to develop and measure processes which include those already accredited.

\subsection{Problem statement and background}

The KwaZulu-Natal Graduate School of Business and Leadership (GSB\&L) is the prominent business school within the KwaZulu-Natal region. The school holds approximately sixty-five percent market share in the region (Charles, 2015). One of the primary reasons for its dominance is the competitive advantage derived from its human capital. It stands to reason that if the school wishes to remain the market leader within the KZN region and South Africa as a whole, then it needs to ensure that it establishes effective brand management strategies to market its MBA programme for it to remain the University of Choice to the South African student population. This is due to its constant failure to appropriately reach out to students in terms of its brand. The main problem is that there is no proper alignment between students and management regarding demands. The failure to do so may result in ineffective strategies being formulated and unsustainable strategic plans implemented, where the school could see its competitive advantage in the KZN region and surrounding areas further diminished. The choice of the business school to pursue an MBA is the biggest decision a prospective student makes. Business schools have adopted marketing and brand management as one of their key strategies to remain competitive and relevant in the market place (Pfeffer \& Fong, 2014). Therefore, the objective of this study was to investigate the UKZN GSB\&L's brand management strategies and its effect on students.

\section{LITERATURE REVIEW}

A prominent brand management strategy integrates an understanding of consumers with the actions of the organisation to build long-term opportunities for growth and profitability (Balmer, 2014). This study sought to present a strategizing framework using a systems perspective to develop strategy metrics for performance measurement and processes for adaptation and learning to modify strategies over time. Concepts such as the strategic systems map, the balanced scorecard, organisational learning, and change management processes, are interpreted and discussed in the context of business schools.

\subsection{Strategic brand management}

A strong brand is viewed as a primary strategic asset for firms. Therefore, the building of a strong brand is a central component of a firm's marketing strategy. However, brand building is always a challenging endeavour, especially in the social media era, as it requires managers to have deep insights on consumer psychology, market competitive dynamics, opportunities and threats associated with social media, and their organisational capabilities (Fournier, 2015).

\subsubsection{Building a winning brand marketing strategy}

A brand marketing strategy determines whether products and services are successful in the marketplace (Sheth \& Sharma, 2015). Today's quickly changing and increasingly global environment requires innovative skills and tools to respond to new consumer demands and habits. Traditional brand strategies are no longer sufficient in reaching customers and convincing them to buy products. Modern tools must be used not only to reach customers where 
they are but also to maintain relationships over a long period. In this context, the management of the brand marketing strategy becomes a key business process for organisations (Naude \& Ivy, 2015).

To be successful a brand marketing strategy has to be based on a strategic planning process associated with the overall business strategy. It needs to take into consideration the profile of the company, its business objectives, as well as the unique selling point (Krippendorf, 2014). Competitive differentiation is what enables companies and products to stand out in today's busy consumer environment. The brand marketing strategy should also be based on corporate vision, mission and values. This contributes to building an internal community of brand ambassadors. Brand marketing strategy should be clearly linked with corporate communications objectives. Corporate communications provide a strategic framework helping to structure marketing efforts, with internal alignment becoming one of the key success factors (Gay, 2015).

A brand marketing strategy must additionally take into consideration the newest trends and technological advances - often not just locally, but globally. These include new communications and social media trends, as well as changes in consumer preferences and practices (Davies, Chun, da Silva \& Roper, 2014). A brand that fails to stay up-to-date and relevant is unlikely to last long. The brand marketing strategy must be frequently reassessed and evaluated. There is no 'silver bullet' guaranteeing success in every marketing campaign. Every individual marketing campaign and associated brand marketing strategy has to take into consideration the context as well as current business objectives. It has to be linked to the true corporate essence and be able to tell its own story. Only in such a way is it possible to build a sustainable, efficient and effective brand marketing strategy (Chun \& Davies, 2014).

\subsubsection{Building brand marketing strategy competencies}

Building a brand marketing strategy requires several skills and competencies. Many business management schools offer courses on marketing and branding and the creation of marketing strategy plans. Some offer even more specialised training, such as in B2B sales and marketing (Ferrandi, Valette-Florence \& Fine-Falcy, 2015). For the best results, it is recommended that one select top international business schools as these provide the highest quality business management courses with the necessary global perspective. To continually develop the best marketing strategies, brand and marketing managers need to frequently update their skill sets and knowledge to keep pace with new developments. On-going executive education is one way to do so, as is attending conferences and other business forums. By staying at the forefront, brand marketing managers can anticipate and leverage new trends - ensuring the best results from their brand marketing strategy (Carmines \& Zeller, 2014).

\subsection{The balanced scorecard framework}

The concept of the Balanced Scorecard (BSC) was first introduced by Robert S. Kaplan and David P Norton in 1996. The basic premise of the BSC is that financial outcomes alone cannot capture value-generating activities. In other words, financial measures are lagging indicators and as such, are not effective in ascertaining the drivers or activities that affect fiscal results. Kaplan and Norton (2014) suggested that organisations, while using financial measures, should develop a comprehensive set of additional measures to use as leading indicators or predictors of financial performance. He suggested that measures should be developed that address four perspectives: 
1. The financial perspective. Measures in this perspective should answer the question, "How should we appear to our shareholders?"

2. The customer perspective. These measures should answer the question, "How should we appear to our customers?"

3. Internal business processes perspective. Measures in this perspective should answer the question, "What processes should we excel at?"

4. Learning and growth perspective. These measures should answer the question, "How can we sustain our ability to change and improve?"

In essence, the Balanced Scorecard is a customer-based planning and process improvement system aimed at directing and driving the change process. It does this by translating strategy into an integrated set of financial and non-financial measures that both communicate the organisational strategy to the members and provide an actionable response on the fulfilment of objectives (Alessandri, 2015). A critical factor for an effective BSC is the alignment of all the measures in the four perspectives with an organisation's vision and strategic objectives. The BSC allows managers to track short-term financial results, while simultaneously monitoring their progress in building the capabilities and acquiring the intangible assets that generate growth for future financial performance (Chang, Otto \& Chee, 2014). Thus, the BSC enables managers to monitor and adjust the implementation of their strategies and to make fundamental changes in them over time (Hooley, Piercy, Nicoulaud \& Rudd, 2017)).

BSC applications focus on for-profit organisations. However, a few studies of the BSC look specifically within business schools for applications. Drtina, Gilbert, and Alon (2015) suggested integrating measures with clearly defined strategies as a first step with various guidelines. Karathanos and Patricia (2005) successfully applied the BSC to a specific master's degree program in business, entrepreneurship, and technology. Papenhausen and Einstein (2015) proposed that a Balanced Scorecard be used in educational institutions for reinforcement of the importance of managing rather than just monitoring performance.

\subsubsection{The balanced scorecard and strategic alignment}

As Kaplan and Norton (2014:75) noted, the earlier version of the balanced scorecard as a multiperspective performance measurement system has changed to take account of strategizing processes and the alignment of strategy with organisational structures and environments. This version has evolved to a new strategic management system, linking long-term strategic objectives with short-term actions, following the usage and experience gained from applying the original scorecard concept in a wide range of 100 or so organisations. Each of those organisations found that the balanced scorecard approach supplied a structure and a framework for such critical management processes as goal-setting, business planning, capital allocations, strategic initiatives and feedback and learning that facilitated strategic thinking and stimulated the analysis of alternative policy options for organisations.

The new strategic management system involves a set of four management processes which interact to enable the management of a balance between short-term productivity objectives and long-term growth perspectives (Chang, 2014). The first of these processes is that involved in the translation of the vision and strategy statements using the model shown in Figure 4 so that they form a clear and well-understood set of objectives and measures that are agreed to and endorsed by all senior managers. This vision/strategy facilitates the framing of the strategy map and identification of long-term drivers, whether marketing, organisation or financial, that will 
determine the long-term success of the school. Ultimately, a well-structured vision and strategy statement builds organisational commitment (Stone, 2015).

The scorecard provides a vehicle for debate and undertakes a strategic role in ensuring that the organisational strategy is understood by all organisational levels and, more importantly, that both departmental and individual objectives are linked and closely aligned to the strategy (Kretovics, 1999). Strategies can be changed or re-oriented, to take account of the real-time learning and feedback achieved by the school and the faculty. Thus, corporate and business unit scorecards can be reviewed and updated. As Kaplan and Norton (2015) point out, the balanced scorecard in this context can be viewed as a systems dynamics model that provides a comprehensive, quantified model of a school's value proposition and enables the corporate strategy and vision to be continually refined and reviewed.

\section{RESEARCH METHODOLOGY}

A descriptive research methodology was used for this study. A survey was administered to a selected sample from a specific population. The term 'survey' is commonly applied to a research methodology designed to collect data from a specific population or a sample from that population, and typically utilizes a questionnaire or an interview as the survey instrument (Strauss \& Corbin, 2015).

The research design is of a quantitative and descriptive nature. Zikmund (2016) explains that the major purpose of descriptive research is to describe the characteristics of a population or phenomenon. This study attempted to establish which brand management strategies affected business school students, specifically referring to the UKZN GSB students. The total population for this study based on the above criteria was 203 students.

A non-probability sampling technique was used which is described by Zikmund (2016) as a sampling technique in which units of a sample are selected based on personal judgement or convenience. Convenience sampling was used to obtain those units or people most conveniently available (Fowler, 2014).

Table 3.1 Target population and a sample of students

\begin{tabular}{|c|c|c|c|}
\hline Population type & Number & Sample & $\%$ Sample \\
\hline Block MiBA stindents 2n year & 105 & 85 & $80 \%$ \\
\hline 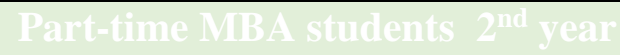 & 98 & 85 & $87 \%$ \\
\hline
\end{tabular}

\subsection{Questionnaires and instrumentation}

A detailed questionnaire was developed for this study. The basis of the questionnaire was the factors and variables that were highlighted in the literature review. The survey addressed two purposes. The first purpose was to examine the perceptions of selected MBA students regarding the quality of the program offered in other business schools as compared to the UKZN GSB, and how the management strategies utilised by these schools have an impact on student choice. The survey instrument was divided into three sections. The survey items in this study were developed as a result of an analysis of previous studies, discussions with professionals in the field, and a review of the literature. 
The second part (Part-B) comprised a series of questions that are generally used to measure student satisfaction. Each statement was measured using a Likert scale (Agree to strongly disagree) and a Dichotomous scale (Yes / No) type of questions.

The survey questionnaire was pre-tested to verify any ambiguity within the instrument. This was done by administering the survey to a subset within the main sample. A subset of ten participants was chosen based on their physical location and accessibility. The results of the pre-test of the questionnaire were reviewed to ensure that there wasn't any ambiguity in the questions.

\subsection{Data collection methods}

Data were gathered by using a self-administered questionnaire which was administered with two forms of distribution. The questionnaire was distributed using the drop-off method and the email survey method. The reason for using the drop-off method was that most of the respondents within the study population and geography of the study are based at the UKZN GSB, and hence obtaining a large number of completed questionnaires would be fairly easy and quick. However, the drop-off method of data gathering did not provide the anticipated number of completed questionnaires and so the email survey method was then utilised.

Participants were not directly chosen when the email survey method was chosen. The surveys were emailed by the researcher to the UKZN GSB and the school was requested to forward the survey to all students within the defined population. All incomplete surveys were discarded from the analysis.

\subsection{Ethics approval}

The ethical clearance for this study was granted by the University of KwaZulu-Natal Humanities and Social Sciences Research Ethics Committee. The respondents were also informed that their participation was voluntary and confidential.

\section{RESULTS}

A total of 191 completed surveys were returned by participants. This included data that was gathered by both the drop-off survey and email survey methods. Of the 191 completed surveys, 21 surveys could not be utilised for data analysis due to the incompletion of surveys by the participants. Common inaccuracies that resulted in surveys being unusable were missing age details and unanswered questions. Of the 200 surveys that were dropped-off, 134 completed surveys were returned by giving a response rate of $67 \%$. The email survey method managed to achieve 36 completed surveys yielding a total of 170 usable responses.

\subsection{Demographic information}

They were 170 students in the sample, of which students of Black African ethnicity made a total of $53 \%$ while students of coloured ethnicity made $3 \%$. Indian and White students made up $20 \%$ and $24 \%$ of the sample respectively.

There was a bigger response rate from the Black ethnic group of MBA students as the majority of these students were Black. Unlike before when educational expectations were lower from black masses as a result of apartheid, after the introduction of BBEE; many blacks now have equal opportunities to education and are predominantly enrolling in these universities to obtain the education that they were previously deprived of to empower themselves.

Of the 170 students that completed the survey, 123 were male students and 47 females. The response rate from both groups was adequate to conduct a statistical analysis. 
The age groups were not originally specified but respondents' actual ages were collected during the survey and ensured a sufficient number of respondents within each group. There were four age groups selected: 26-30 years, 31-39 years, 40-49 years, and greater than 50 years. The number of respondents in each group was $27,86,32$ and 25 respectively.

\subsection{Factor analysis}

A factor analysis was conducted using the responses from the 170 students which aimed to take the questions from the survey and reduce them into a smaller number of facts that would represent the objective of the study. To verify if the data set was suitable for factor analysis, the strength among the statements was tested using the KAISER-Meyer-Olkin (KMO) measure of sampling adequacy and Bartlett's test of sphericity. Hoepfl (2015) suggests that Bartlett's test of sphericity should be significant at the 5\% level and the KMO value should exceed 0.6 for factor analysis to be considered. The table below presents the results of the KMO measure and Bartlett's test. In this study, the KMO value is 0.822 greater than 0.6 and Bartlett's test of sphericity value was significant at the $5 \%$ level (the significance value is $\prec 0.05$ ); hence the data set was appropriate for factor analysis.

Table 4.1 KMO and Bartlett's Test

\begin{tabular}{|l|l|l|}
\hline \multicolumn{2}{|c|}{ KMO and Bartlett's test } & \\
\hline \multicolumn{2}{|c|}{ Kaiser-Meyer-Olkin Measure of Sampling Adequacy } & 0.822 \\
\hline Bartlett's Test of Sphericity & Approx. Chi-Square & 2.851 .083 \\
\hline & Sig. & 0.000 \\
\hline
\end{tabular}

To determine the number of factors to extract, the eigenvalues, percentage variance explained were considered. The scree plot, which is shown in the figure below, shows that there were several factors with eigenvalues above one.

The table below reports the eigenvalues, percentage variance explained and Cronbach Alpha for each of the three strategies. The eigenvalues for three strategies were 9.563, 2.978 and 2.583 respectively and the variance explained by each of the three strategies was $24.73 \%, 6.71 \%$ and $5.63 \%$ respectively. The total variance explained by the three strategies was $37.07 \%$. Although the total variance explained by the three strategies is lower than the desired $50 \%$, the scree plot indicated that a three strategic framework would be appropriate. The Cronbach Alpha for each of the three strategies was also high, $0.8726,0.8464$ respectively, and indicates that the statements contained within each factor are closely related and measure the underlying factor respectively.

Table 4.2: Distribution of eigenvalues

\begin{tabular}{|l|l|l|l|}
\hline & Strategy 1 & Strategy 2 & Strategy 3 \\
\hline Eigenvalue & 9.563 & 2.978 & 2.583 \\
\hline \% Variance explained & 24.73 & 6.71 & 5.63 \\
\hline Cumulative \% & 24.73 & 31.44 & 37.07 \\
\hline Cronbach Alpha & 0.873 & 0.846 & 0.846 \\
\hline
\end{tabular}




\subsection{Results for proposition one}

Proposition one aimed to test whether the UKZN GSB brand management strategies for the MBA programme would have a different effect on men and women. The results for gender group comparison are shown in the table below. The results show that Strategy one is equally important to men as it is to women (p-value > 0.05) and that Strategy two and Strategy three are more important to women than they are to men (both Strategy one and Strategy two pvalues are less than 0.005$)$.

Table 4.2 Results of gender group comparisons

\begin{tabular}{|c|c|c|c|c|c|}
\hline \multicolumn{6}{|c|}{ GENDER (A) } \\
\hline Strategy & Group & $\mathbf{N}$ & Mean & Std Dev & P-Value \\
\hline \multirow[t]{2}{*}{ S1 } & Males & 123 & 5.9805 & 0.6079 & \multirow[t]{2}{*}{0.0966} \\
\hline & Females & 47 & 6.1333 & 0.3779 & \\
\hline \multirow[t]{2}{*}{$\mathbf{S 2}$} & Males & 123 & 5.8421 & 0.7159 & \multirow[t]{2}{*}{0.0052} \\
\hline & Females & 47 & 6.2163 & 0.4364 & \\
\hline \multirow[t]{2}{*}{ S3 } & Males & 123 & 5.1075 & 0.988 & \multirow[t]{2}{*}{0.0255} \\
\hline & Females & 47 & 5.4161 & 0.6249 & \\
\hline \multicolumn{6}{|c|}{ GENDER: REPEATED MEASURES ANOVA (B) } \\
\hline Strategy & Mean & Comparison & Group & $\mathbf{N}$ & P-Value \\
\hline S1 & 5.9805 & $\mathrm{~S} 1-\mathrm{S} 2$ & Males & 123 & 0.0237 \\
\hline S2 & 5.8421 & S2-S3 & Males & 123 & $>0.0001$ \\
\hline $\mathbf{S 3}$ & 5.1075 & S1-S3 & Males & 123 & $>0.0001$ \\
\hline S1 & 6.1333 & $\mathrm{~S} 1-\mathrm{S} 2$ & Females & 47 & 0.1385 \\
\hline $\mathbf{S 2}$ & 6.2163 & S2-S3 & Females & 47 & $>0.0001$ \\
\hline S3 & 5.416 & S1-S3 & Females & 47 & $>0.0001$ \\
\hline
\end{tabular}

The repeated measure ANOVA for the gender group comparison shows that Inspirational leadership (Strategy one) is the most important for men. For women, Strategy one and Strategy two are equally more important than Strategy three.

\subsection{Results for research proposition two}

The aim of research proposition two was to test whether the UKZN GSB brand management strategies for the MBA programme would have a different effect on students' different age groups. The table below presents the results for the age group comparisons. The ages were clustered into four groups: 26-30, 31-39, 40-49 and greater than 50. From the age group comparison table below, it is seen that there are no differences in the means between each age 
group, for each strategy respectively. Hence Strategy one is of the same importance for each age group. The same is concluded for Strategy two and Strategy three.

The means of each strategy were then compared within each age group to determine the most important strategy for each age group and whether the difference within each age group was significant at the 5\% level. The results indicated that for the first two age groups (26-30 and 31-39) strategy one and strategy two are equally the most important and both are more important than strategy three. For the second two age groups (40-49 and 50+) strategy one is the most important, strategy two is the second most important and strategy three the third most important. This indicates that a difference in the importance of strategies exists between the younger two age groups (26-30 and 31-39) and the older two age groups (40-49 and 50+). The results show strategy two is more important to the younger two age groups than it is for the older age groups.

Table 4.3 Results of age group comparisons

\begin{tabular}{|c|c|c|c|c|c|}
\hline \multicolumn{6}{|c|}{ AGE (A) } \\
\hline Strategy & Group & $\mathbf{N}$ & Mean & Std Dev & P-Value \\
\hline \multirow{4}{*}{ S1 } & $26-30$ & 27 & 6.0494 & 0.6356 & \multirow{4}{*}{0.9743} \\
\hline & 31-39 & 86 & 6.0379 & 0.5769 & \\
\hline & $40-49$ & 32 & 6.0417 & 0.5042 & \\
\hline & $50+$ & 25 & 5.9173 & 0.4766 & \\
\hline \multirow{4}{*}{ S2 } & $26-30$ & 27 & 6.2130 & 0.4980 & \multirow{4}{*}{0.7438} \\
\hline & 31-39 & 86 & 6.0116 & 0.5945 & \\
\hline & $40-49$ & 32 & 5.8310 & 0.6708 & \\
\hline & $50+$ & 25 & 5.5770 & 0.9007 & \\
\hline \multirow{4}{*}{$\mathbf{S 3}$} & $26-30$ & 27 & 5.2839 & 1.0429 & \multirow{4}{*}{0.8085} \\
\hline & 31-39 & 86 & 5.1434 & 0.8745 & \\
\hline & $40-49$ & 32 & 5.2569 & 1.0811 & \\
\hline & $50+$ & 25 & 5.1822 & 0.6501 & \\
\hline \multicolumn{6}{|c|}{ AGE: REPEATED MEASURES ANOVA (B) } \\
\hline Strategy & Mean & Comparison & Group & $\mathbf{N}$ & P-Value \\
\hline S1 & 6.0494 & S1-S2 & 26-30 & 27 & 0.0779 \\
\hline $\mathbf{S 2}$ & 6.2130 & S2-S3 & 26-30 & 27 & $<0.0001$ \\
\hline $\mathbf{S 3}$ & 5.2839 & S1-S3 & 26-30 & 27 & $<0.0001$ \\
\hline S1 & 6.0379 & S1-S2 & 31-39 & 86 & 0.6625 \\
\hline S2 & 6.0116 & S2-S3 & 31-39 & 86 & $<0.0001$ \\
\hline
\end{tabular}


2nd International Conference on Research In MANAGEMENT

\begin{tabular}{|l|l|l|l|l|l|}
\hline S3 & 5.1434 & S1-S3 & 31-39 & $\mathbf{8 6}$ & $<0.0001$ \\
\hline \multicolumn{7}{|l|}{$\mid$} \\
\hline S1 & 6.0417 & S1-S2 & $\mathbf{4 0 - 4 9}$ & $\mathbf{3 2}$ & 0.0489 \\
\hline S2 & 5.8310 & S2-S3 & $\mathbf{4 0 - 4 9}$ & $\mathbf{3 2}$ & 0.0002 \\
\hline S3 & 5.2569 & S1-S2 & $\mathbf{4 0 - 4 9}$ & $\mathbf{3 2}$ & $<0.0001$ \\
\hline \multicolumn{7}{|l|}{} \\
\hline S1 & 5.9173 & S1-S2 & $\mathbf{5 0 +}$ & $\mathbf{2 5}$ & 0.0499 \\
\hline S2 & 5.5770 & S2-S3 & $\mathbf{5 0 +}$ & $\mathbf{2 5}$ & 0.0193 \\
\hline S3 & 5.1822 & S1-S3 & $\mathbf{5 0 +}$ & $\mathbf{2 5}$ & $<0.0001$ \\
\hline
\end{tabular}

\subsection{Results for research proposition three}

Proposition three aimed to test whether the UKZN GSB brand management strategies for the MBA programme would have a different effect on students' ethnic/racial groups. The table below illustrates the results for the ethnic group comparisons. The results show that it is only for strategy two that a significant difference between the means exists. The mean on strategy two for the white ethnic group differs significantly at the 5\% level from the other three ethnic groups. This shows that strategy two is less important to white students than it is for black, Indian and coloured students.

The table below also shows that for the black ethnic group, Seasonal apprenticed mentorships (strategy two) is the most important strategy to influence students. For white students, inspirational leadership (strategy one) is the most important. Strategy one and two are equally the most important to students of Indian ethnicity. The results for the coloured sub-group were not considered for the repeated measures ANOVA due to the small sample size $(\mathrm{N}=5)$.

Table 4.4 Results of ethnicity group comparisons

\begin{tabular}{|l|l|l|l|l|l|}
\hline \multicolumn{5}{|c|}{ ETHNICITY (A) } \\
\hline \multirow{3}{*}{ Strategy } & Group & N & Mean & Std Dev & P-Value \\
\hline \multirow{5}{*}{ S1 } & Black & 90 & 5.9992 & 0.6383 & 0.5019 \\
\cline { 2 - 5 } & White & 41 & 5.9691 & 0.4216 & \\
\cline { 2 - 5 } & Indian & 34 & 6.1529 & 0.4715 & \\
\cline { 2 - 5 } & Coloured & 5 & 6.0000 & 0.4989 & \\
\cline { 1 - 5 } & Black & 90 & 6.1315 & 0.5505 & \multirow{2}{*}{0.0006} \\
\cline { 2 - 5 } & White & 41 & 5.4919 & 0.7683 & \\
\cline { 2 - 5 } & Indian & 34 & 6.0267 & 0.6191 & \\
\cline { 2 - 5 } & Coloured & 5 & 5.7660 & 0.4691 & \\
\hline
\end{tabular}


2nd International Conference on Research In MANAGEMENT

$19 \_21$ February, 2021

Vienna, AUSTRIA

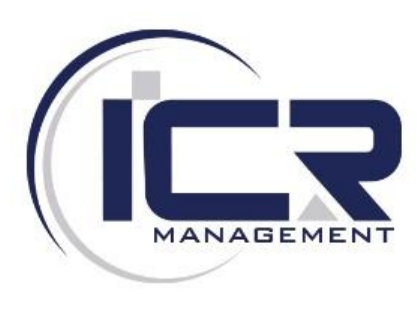

\begin{tabular}{|l|l|l|l|l|l|}
\hline \multirow{3}{*}{ S3 } & Black & 90 & 5.1037 & 0.9780 & \multirow{2}{*}{0.1530} \\
\cline { 2 - 5 } & White & 41 & 5.1653 & 0.8965 & \\
\cline { 2 - 5 } & Indian & 34 & 5.4575 & 0.7648 & \\
\cline { 2 - 5 } & Coloured & 5 & 5.2222 & 0.3600 & \\
\hline
\end{tabular}

\section{DISCUSSION}

The issue that was investigated concerned why students had these negative perceptions about the school in the first place. What negativity was derived from the school's management team which resulted in these perceptions to students? There may be several reasons for this. Firstly, most students are concerned about the school's MBA programme curriculum which runs for a full 30 months to complete, whereas other business schools in South Africa run the programme for only 24 months (Yucelt, 2014). Other negativities for such perceptions concern why the school cannot retain its lecturers and management. As a consequence, it has resulted in a misalignment between the students and the management team due to the failure of these professionals to maintain a consistent strategic plan to run the school as required. Sometimes lecturers are even being changed close to exam time and this causes much confusion amongst students because they cannot keep up with the different teaching styles of the lecturers. This is why most students graduate with an MBA qualification from the UKZN GSB but are still not ready for the job market as they lack the necessary skills to compete, due to a lack of proper lecture training from lecturers who are changed occasionally by the school (Crainer \& Dearlove, 2015). Therefore, since these negativities are less likely to come up in leading business schools, it stands to reason that the existing students would be more enticed to apply for tuition at those few leading schools.

The first objective of the study was to evaluate the effectiveness of the UKZN GSB brand identity/management strategies for the MBA programme and to then determine which of these strategies was most important. It was found that there were statistical significance and associations. The Friedman test indicated that a statistically significant difference existed between the three strategies with a p-value $<0.0001$. To determine which strategies the difference was significant, a Friedman Multiple Comparison Test was conducted, the results of which are reported in the table below. The results show that strategy three differs from strategy one and strategy two at the 5\% level. Strategy one is not significantly different from strategy two at the 5\% level and hence the conclusion is that Inspirational leadership (Strategy one), and Seasonal apprenticed mentorships (Strategy two) are equally the most important strategies to an effective UKZN GSB brand identity strategy for the MBA programme.

The study was to assess the UKZN GSB brand awareness level of its MBA programme amongst the UKZN student population. The findings indicated that approximately seventy percent of students within the UKZN are not aware of the MBA programme offered as it is not visibly marketed to all students (Abratt, 2015). Most of the current MBA students were also not aware that the GSB existed before enrolling into the programme. The majority of them became aware of the school from previous students' word of mouth, rather than seeing adverts or marketing material that promoted the school. The school needs to, therefore, focus its advertising on students and utilise top-class marketing campaigns such as radio interviews, television adverts, billboards etc., to attract awareness and remain competitive. If the UKZN 
student population is not aware of the school while they are within, how does one expect South Africa's student population to be aware? And while objective three evaluated the UKZN GSB brand communication strategy and its effect within SA's student population, it had the same results as the $2^{\text {nd }}$ objective as students shared the similar sentiments about its brand communication strategy. The UKZN GSB as a brand is not well communicated to the public, simply because the school lacks the necessary resources to project its image or maybe just simply taking it for granted that they need to excel in their brand marketing strategies to be on top. The school does not even engage with MBA students in occasional debate conferences with other MBA students from competing business schools to empower the students and to promote the UKZN as a brand by being involved in such initiatives. The school has brand management strategies in place, but they are not implemented appropriately to promote the brand (Roberts \& Binder, 2015).

The literature and research have emphasized that several factors can validate that strategic influences can be successfully used in a school's strategic plan. These include motivating factors such as career growth, job position and promotions. Interestingly, these factors did not demonstrate as having a significant association with all respondents of the survey. The appealing factors only emerged as having a significant association with students within the programme. The implications of this finding are that the UKZN GSB would not likely be in a position to entice students from outside the KZN region using those particular motivating factors. However, it did mean that they could use the factors to influence students from within KZN to remain in and accept the management's strategic plans to improve the school's brand and marketing strategies thus eliminating existing negative perceptions from the minds of future MBA candidates. However, the challenge that remains is the scarcity of competencies and skills of lecturers within the school. The findings in this study have provided much insight into the options available to the UKZN GSB in the use of brand management strategies as strategic tools in maintaining a competitive advantage in the $\mathrm{KZN}$ region and surrounding provinces.

\section{CONCLUSION}

In a competitive industry, business schools need to grasp at any source of competitive advantage that it can find. The UKZN GSB recognises this fact and therefore places much emphasis on remaining a leading player in KwaZulu-Natal and overall South Africa's student population. One of the key reasons for its high market share in this province and the main source of competitive edge lies in the school's ability to source critical human capital. To sustain this strategy, the UKZN GSB must continue to strategically use its brand management strategies as a tool to maintaining its existing competitive advantage in $\mathrm{KZN}$ and to be able to retain its students, lecturers and management.

\section{RECOMMENDATIONS}

For the UKZN GSB management to improve overall institutional effectiveness, a deeper understanding of the brand management strategies is required to influence student choice positively. The UKZN GSB needs to establish a clear and meaningful strategic planning process and engage with students to ensure success. An innovation process for all new product (MBA programme) development, service delivery, strategies should be applied. The creation of projects to manage the strategies and prioritize all of these projects to ensure they are properly resourced should be implemented. Re-shaping the institutional culture to be more adaptive to the changes in the strategic plan should be adhered to. 


\section{REFERENCES}

Abratt, R. (2015). A new approach to the corporate image management process. Journal of Marketing Management, Vol. 5, No. 1:63-76.

Alessandri, S.W. (2015). Modelling corporate identity: A concept explication and theoretical explanation, Corporate Communications: An International Journal, Vol. 6, No. 4:173182.

Balmer, J.M.T. (2014). Corporate branding and connoisseurship. Journal of General Management, Vol. 21, No. 1:24-46.

Carmines, E. \& Zeller, R. (2014). Reliability and validity assessment. Beverly Hills, California: Sage Publications.

Chang, Otto H. \& Chee W. Chow (2014). The Balanced Scorecard: A potential tool for supporting change and continuous improvement in accounting education. Issues in Accounting Education. Aug, Vol. 14 Issue 3:395-413.

Charles, C.M. (2015). Introduction to educational research $\left(2^{\text {nd }}\right.$ Ed.). San Diego: Longman.

Chun, R. \& Davies, G. (2014). E-reputation: The role of mission and vision statements in positioning strategy. The Journal of Brand Management, Vol. 8, No. 4-5: 315-333.

Crainer, S. \& Dearlove, D. (2015). Gravy training: Inside the business of business schools. San Francisco: Jossey-Bass Publishers.

Davies, G., Chun, R., da Silva, R.V. \& Roper, S. (2014). The personification metaphor as a measurement approach for corporate reputation. Corporate Reputation Review, Vol. 4, No. 2:113-127.

Drtina, R., Gilbert, J.P. \& Alon, I. (2015). Using the balanced scorecard for value congruence in an MBA educational setting. Sam Advanced Management Journal. Winter, Vol. 72 Issue 1:4-13.

Ferrandi , J.M., Valette-Florence, P. \& Fine-Falcy, S. (2015). Aaker's brand personality scale in a French context: A replication and preliminary test of its validity. Developments in Marketing Science, Vol. 23:7-13.

Fournier, S. (2015). Consumer and their brands: Developing relationship theory in consumer research. Journal of Consumer Research, Vol. 24, No. 4:343-373.

Fowler, F.J. Jr. (2014). Improving survey questions: Design and evaluation. Applied Social Research Methods Series, 38. Thousand Oaks, California: Sage Publications.

Gay, L. (2015). Educational research: Competencies for analysis and application. Columbus: Merrill Pub. Co.

Hoepfl, M.C. (2015). Choosing qualitative research: A primer for technology education researchers. Journal of Technology Education, 9(1):47-63. DOI: 10.21061/jte.v9i1.a.4.

Hooley, G., Piercy, N., Nicoulaud, B. \& Rudd, J. (2017) Marketing strategy \& competitive positioning, South Africa: Pearson Education. 
Kagan, J. (2015). MBA South Africa: A strategic guide to selecting your MBA programme and school. Cape Town: Zebra Press.

Kaplan, R.S. \& Norton, D.P. (2014). The balanced scorecard: Measures that drive performance. Harvard Business Review, 70:71-79.

Kaplan, R.S. \& Norton, D.P. (2015). Strategy maps. Boston, MA: Harvard Business School Publishing Corp.

Karathanos, D. \& Karathanos, P. (2005). Applying the balanced scorecard to education. Journal of Education for Business. Mar/Apr 2005, Vol 80 issue 4:222-230. DOI:10.3200/JOEB.80.4.222-230.

Krippendorf, K. (2014). Content analysis: An introduction to its methodology. $2^{\text {nd }} E d$. Thousand Oaks, CA: Sage Publications.

Kretovics, M.A. (1999). Assessing the MBA: What do our students learn? The Journal of Management Development, Volume 18, Issue 2.

Naude, P. \& Ivy, J. (2015). The marketing strategies of universities in the United Kingdom. The International Journal of Educational Management, Vol.13 (3):126-134.

Papenhausen, C. \& Einstein, W. (2015). Insights from the balanced scorecard: Implementing the balanced scorecard at a college of business. Emerald Group Publishing Limited. Vol. 10 Issue 3: 15-22.

Pfeffer, J. \& Fong, C.T. (2014). The ends of business school? Less success than meets the eye. Academy of Management Learning and Education, Vol. 1, No. 1: 78-95.

Roberts G.R. \& Binder, D.A. (2015). Design-based methods for estimating model parameters. In Analysis of Survey Data. R.L. Chambers and C.J. Skinner (eds.) Chichester. Wiley. pp. 29-48.

Sheth, J.N. \& Sharma, A. (2015). International e-marketing: Opportunities and issues. International Marketing Review, Vol. 22, No. 6: 611-622.

Stone, P.J. (2015). Thematic text analysis: New agendas for analysing text content. in C.W. Roberts (ed.) Text Analysis for the Social Sciences: Methods for drawing inferences from texts and transcripts. Publisher: Erlbaum, Mahwah, NJ, pp. 35-54.

Strauss, A. \& Corbin, J. (2015). Basics of quantitative research: Grounded theory procedures and techniques. Newbury Park, CA: Sage Publications, Inc.

Yucelt, U. (2014). Comparative study of students' perception on quality of MBA programs. Journal of International Marketing and Marketing Research, Vol. 23, No. 1:27-33.

Zikmund, W.G. (2016). Business research methods. United States: South Western. 